\title{
Reconstrucción mamaria en Síndrome de Poland Severo
}

\author{
Breast reconstruction in Severe Poland Syndrome
}

\author{
Miguel García Wenninger ${ }^{1,2, a}$, Jose Sandoval Pere $z^{1,2, b},{ }^{\bullet}$ Celso Aldana Ubilus ${ }^{1,2, b}$ \\ 1. Universidad Nacional de Asunción, Facultad de Ciencias Médicas, Hospital de Clínicas, \\ Unidad de Cirugía Plástica Reconstructiva y Estética. San Lorenzo, Paraguay \\ 2. Sociedad Paraguaya de Cirugía Plástica y Reconstructiva. Asunción, Paraguay
}

\section{RESUMEN}

El síndrome de Poland es una malformación congénita infrecuente, caracterizada por hipoplasia de la mama y el pezón, escasez de tejido subcutáneo y ausencia de la porción esternal del músculo pectoral mayor. Presentamos el caso de una paciente de 25 años en el que se realiza una reconstrucción con colgajo de dorsal ancho, expansor tisular, prótesis mamaria de silicona y lipofilling mamario más injerto de pezón y areola en varias etapas.

Palabras clave: Colgajo dorsal ancho, síndrome de poland, prótesis mamaria.

\section{ABSTRACT}

Poland syndrome is a rare congenital malformation, characterized by hypoplasia of the breast and nipple, lack of subcutaneous tissue, and absence of the sternal portion of the pectoralis major muscle. We present the case of a 25-year-old patient who underwent reconstruction with a latissimus dorsi flap, tissue expander, silicone breast prosthesis, and breast lipofilling plus nipple and areola grafting in various stages.

Keywords: Latissimus dorsi flap, Poland syndrome, breast implant.

\section{INTRODUCCIÓN}

El Síndrome de Poland fue descrito en la literatura inglesa en $1841^{(1)}$. Consiste en la agenesia unilateral del músculo pectoral mayor acompañada o no por sindactilia/braquidactilia homolateral, agenesia o hipoplasia de otros músculos de la pared torácica, atelia, amastia o hipoplasia mamaria y costillas deformes o ausentes. La anomalía principal y constante de esta malformación es la ausencia del fascículo esternocostal del músculo pectoral mayor que se traduce clínicamente en una depresión infraclavicular y ausencia del pliegue anterior de la axila. Aparece de forma esporádica en 1 de cada 30000 recién nacidos vivos ${ }^{(2)}$. Es más frecuente en el lado derecho $(75 \%)^{(3)}$ y más prevalente en varones $(3: 1)^{(4)}$.

\section{REPORTE DE CASO}

Paciente de 25 años, que acudió a la consulta de la Unidad de Cirugía Plástica por presentar desde su nacimiento ausencia de la mama derecha. Al examen físico se constató la ausencia de la mama derecha, así como del músculo pectoral mayor y del menor y un pezón rudimentario sin areola (Figura 1). Se concluyó el diagnóstico como un síndrome de Poland, consistente en una amastia con ausencia de ambos músculos pectorales (estadio III de Foucras).

La reconstrucción se realizó en tres tiempos, en la primera un colgajo músculo-cutáneo de latissimus dorsi complementado con expansor tisular (Figura 2), en la segunda intervención, cambio de expansor por prótesis mamaria siliconada lisa de 325 cc e injerto del pezón y en la tercera remodelación de cicatrices más lipofilling en la región infraclavicular e injerto de areola (Figura 3).
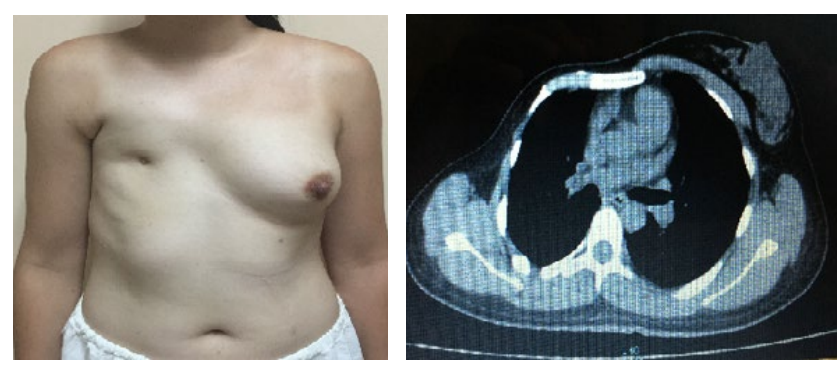

Figura 1. Aplasia de la mama derecha con hipoplasia del complejo areola - pezón. 

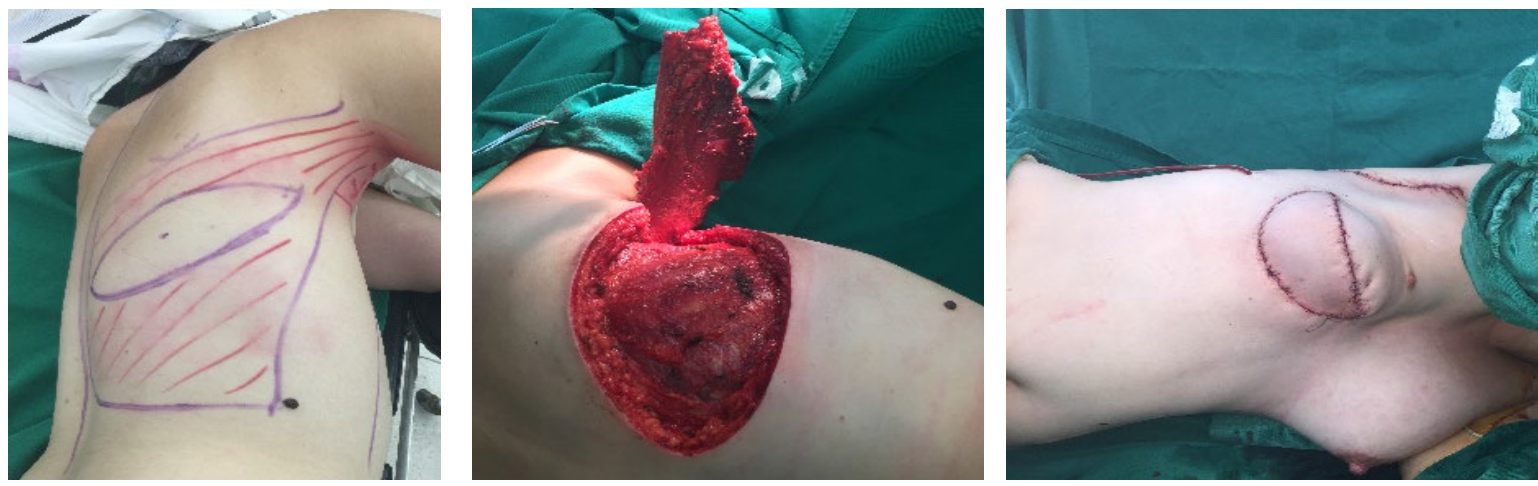

Figura 2. Diseño del colgajo miocutáneo latissimus dorsi derecho y colocación de expansor.
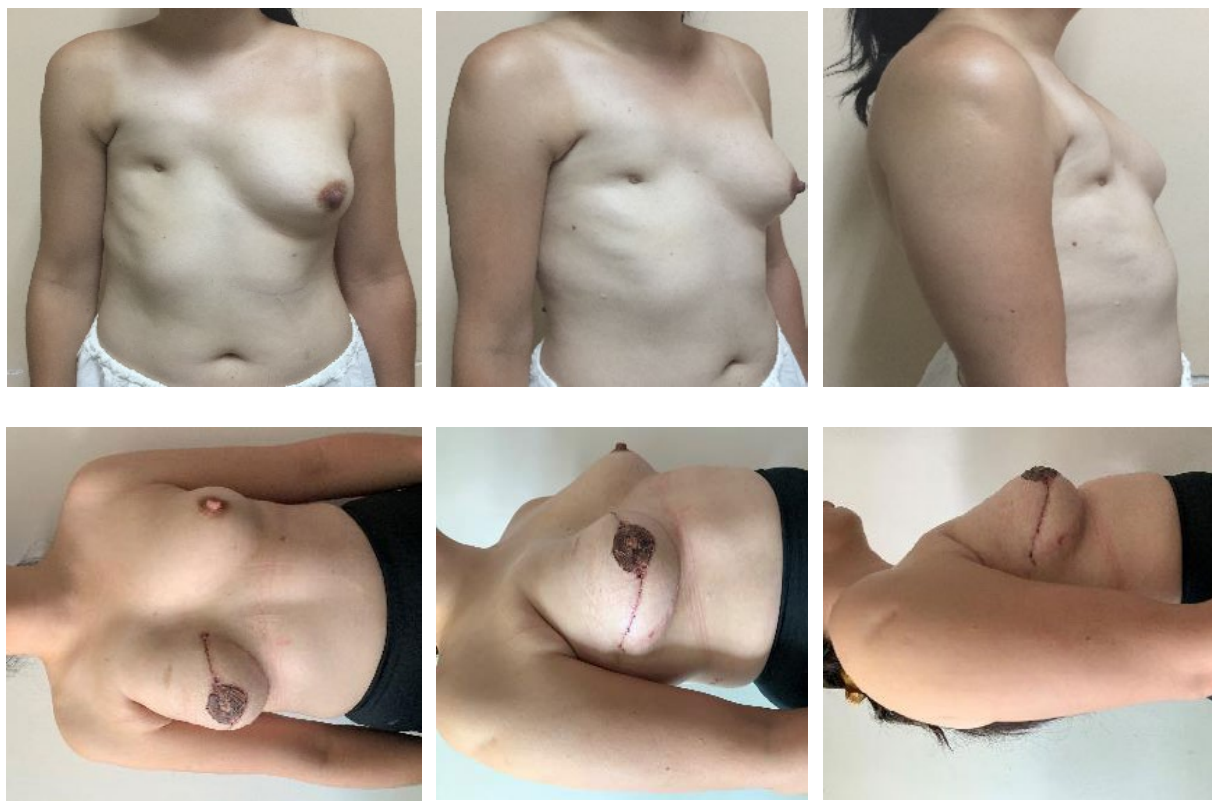

Figura 3. Pre y post-operatorio.

\section{DISCUSIÓN}

El Síndrome de Poland puede presentarse de maneras muy diversas dependiendo del tipo de severidad por lo que el cirujano debe estar familiarizado con todos los tipos de cirugías que este tipo de malformación requiere: colgajos miocutáneos, utilización de expansores cutáneos, prótesis mamarias, pexia o reducción mamaria e injertos de piel y colgajos locales para la reconstrucción del complejo areola - pezón. Asimismo, debe estar en capacidad de resolver las complicaciones que se pueden

\section{REFERENCIAS BIBLIOGRÁFICAS}

1. Poland A. Deficiency of the pectoralis muscles. Guys Hosp Rep 1841;6:191-3.

2. Grosfeld JL, O'Neill JA, Fonkalsrud EW, Coran AG. Pediatric Surgery 6 ${ }^{\mathrm{a}}$ ed 2006; 907-12.

3. Mysnyk MC, Johnson DE. Congenital absence of the pectoralis muscle in two collegiate wrestling champion. Clin Orthop 1991; 265:183-6.

4. Shamberger RC, Welch KJ, Upton J. Surgical treatment of thoracic deformity in Poland's syndrome. J Pediatr Surg 1989;24:760-5. presentar. 